\title{
Caracterización experimental y simulación computacional de la fatiga muscular
}

\author{
Marta Sierra $^{1}$, M $^{\mathrm{a}}$ Jesús Muñoz ${ }^{2}$, Jorge Grasa ${ }^{1}$ \\ ${ }^{1}$ AMB (Grupo de Mecánica Aplicada y Bioingeniería) \\ Edificio Agustín de Betancourt; C/María de Luna, 7; 50018-Zaragoza \\ Tel: +34876555107/Fax: +34976762578 \\ ${ }^{2}$ LAGENBIO (Laboratorio de Genética Bioquímica de la Universidad de Zaragoza) \\ Facultad de Veterinaria; C/Miguel Servet 177 \\ 50013, Zaragoza, Spain. \\ Tel: + 34976761621 /Fax: + 349767616122
}

\section{Resumen}

El objetivo principal de este trabajo comprende la caracterización de la fatiga múscular así como su simulación computacional. El estudio se ha llevado a cabo sobre el músculo Tibial Anterior (TA) de 5 ratas Wistar en las cuales se registra la fuerza desarrollada y la evolución de la concentración de glucógeno.

\section{Introducción}

La fatiga muscular es el estado en el que un músculo pierde su capacidad de contraerse ante un estímulo. Este estado es biologicamente muy complejo y todavía no se conoce exactamente cuáles son los mecanismos y las causas que provocan su aparición. Dentro de las múltiples causas que se contemplan está la depleción del glucógeno, fuente de energía principal del músculo que, junto con otros factores, conducirían al músculo hasta la fatiga total.

Los modelos de simulación computacional son desarrollados con el objetivo de comprender y estudiar en profundidad sistemas complejos que dependen de numerosas variables. En estudios previos nuestro grupo ha creado modelos computacionales para el estudio del comportamiento muscular $(1,2)$. Entre los músculos previamente estudiados se encuentra el Tibial Anterior (TA), en el que predominan las fibras de tipo IIb también conocidas como fibras de contracción rápida.

Con la finalidad de desarrollar un modelo computacional que simule el proceso de fatiga del músculo TA, éste se ha caracterizado de manera experimental en el laboratorio estudiando la evolución de la fuerza desarrollada a lo largo del tiempo. Además, se ha incorporado el estudio de una variable biológica, como es la cinética de consumo del glucógeno almacenado en el propio músculo, con la intención de aumentar la precisión del modelo y permitir un estudio más profundo de la relación entre caída de la fuerza (fatiga) y el agotamiento del glucógeno.

\section{Material y Métodos}

En este trabajo se han utilizado 5 ratas Wistar machos de dos meses de edad con pesos de 313+/$81,14 \mathrm{~g}$. Los animales fueron suministrados por Laboratorios Harlan y se mantuvieron de acuerdo a la legislación vigente en experimentación animal. Todos los experimentos han sido aprobados por el Comité Ético de la Universidad de Zaragoza para el uso de animales de experimentación.

La disección del músculo se realizó según describe en (2). Para la estimulación eléctrica del músculo se aplicaron en el nervio ciático trenes de $200 \mathrm{~ms}$, $8 \mathrm{~V}$ y $90 \mathrm{~Hz}$, a intervalos de $800 \mathrm{~ms}$. La estimulación se mantuvo durante una hora con el objetivo de alcanzar el estado de fatiga.

Los músculos fueron extraídos y congelados en nitrógeno líquido. La extracción y determinación del glucógeno se realizó por el método descrito en (3). Se determinó en músculos control, músculos sometidos a siete minutos de estimulación y en músculos al final del ensayo, tras una hora de estimulación.

El modelo computacional de elementos finitos desarrollado, incorpora una formulación hiperelástica transversalmente isótropa para simular el comportamiento pasivo (1).

Para incorporar el comportamiento activo, la evolución de la tensión desarrollada por el tejido se han propuesto las siguientes relaciones:

$$
\begin{aligned}
& \sigma=\sigma_{0} \cdot f_{\text {activ }}(t) \\
& f_{\text {activ }}(t)=\frac{A(t)}{1+e^{\left(-B(t) t+\left(1+i \cdot t_{d}\right) t_{i}\right)}} \cdot \frac{C(t) \cdot t+1}{1+e^{\left(D(t) t+\left(1+i \cdot t_{d}\right) t_{f}\right)}}
\end{aligned}
$$

Donde s0 es la tensión isométrica máxima capaz de generar el músculo, $\mathrm{A}(\mathrm{t})$ controla la variación de la amplitud, $\mathrm{B}(\mathrm{t})$ y $\mathrm{D}(\mathrm{t})$ las pendientes de subida y bajada del pulso de la contracción y $\mathrm{C}(\mathrm{t})$ regula la pendiente dentro del pulso.

\section{Resultados}

Los resultados de fuerza obtenidos muestran unos valores máximos medios de $6.6 \mathrm{~N}$ al inicio de la estimulación y de $1.1 \mathrm{~N}$ al final de la misma. La caída de la fuerza no se produce de manera 
uniforme, en la primera parte, que corresponde aproximadamente a los diez primeros minutos de estimulación, la fuerza cae con una pendiente mucho más pronunciada que en el segundo tramo de la misma, en la que la pendiente es mínima. (Figura 1)

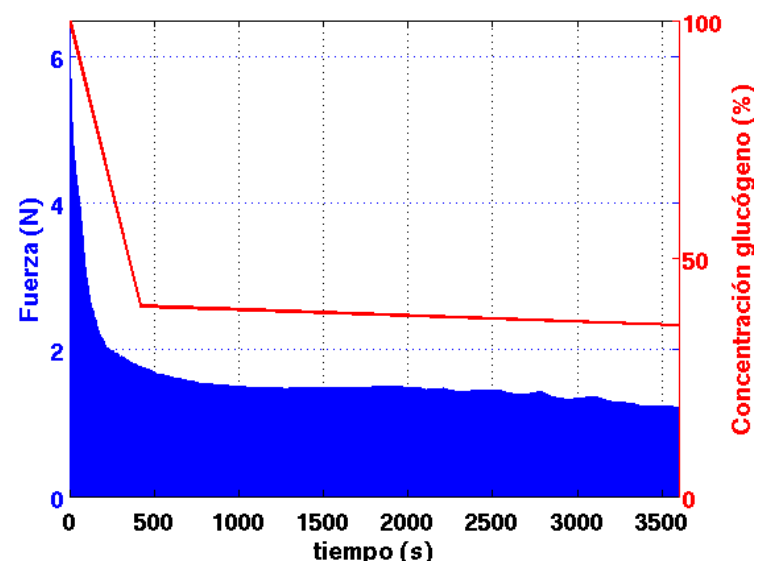

Figura 1. Evolución de la fuerza y concentración del glucógeno a lo largo del tiempo en el músculo TA.

Al medir la cantidad de glucógeno almacenado en este mismo músculo, se observó que disminuye a un tercio de su valor inicial en el primer tramo de estimulación y se mantiene en esos valores hasta el final del protocolo completo (una hora). (Figura 1)

Estos resultados nos permiten comparar la desaparición del glucógeno con la caída de fuerza observada a nivel experimental. Ambas evolucionan de forma paralela, lo que evidencia la existencia de una relación entre ambas. Por tanto, la disminución de la fuerza observada podría explicarse en gran medida como consecuencia de una caída en el principal sustrato energético de las fibras musculares, el glucógeno, tal y como se observa en la Figura 1. La fatiga del músculo se produce además como consecuencia de un conjunto de factores como es la acidificación del $\mathrm{pH}$, la disminución de la sensibilidad al calcio o la ausencia de ATP.

La Figura 2 representa el comportamiento experimental y el computacional superpuestos. En ambos casos, la fuerza registrada a tiempo cero es de seis newtons y va disminuyendo a lo largo del procedimiento. Como puede observarse, el comportamiento computacional (Fig 2 y 3 ) se ajusta a los datos experimentales.

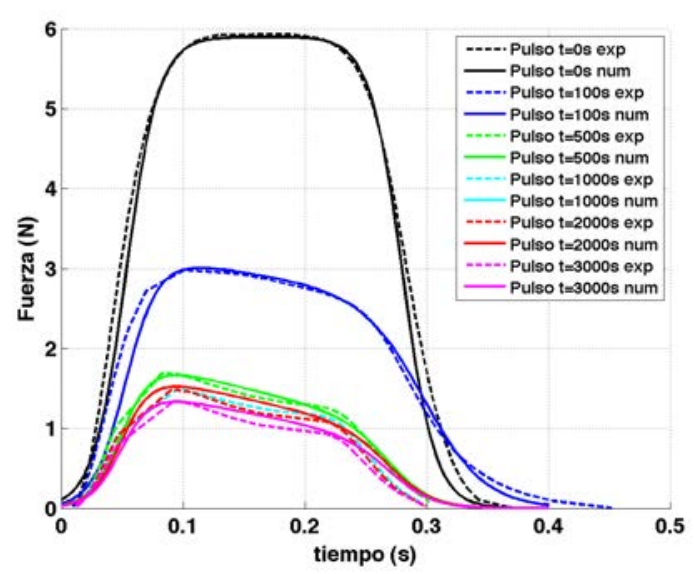

Figura 2. Evolución de la fuerza desarrollada por el músculo en cada uno de los pulsos individuales y ajuste realizado con el modelo.

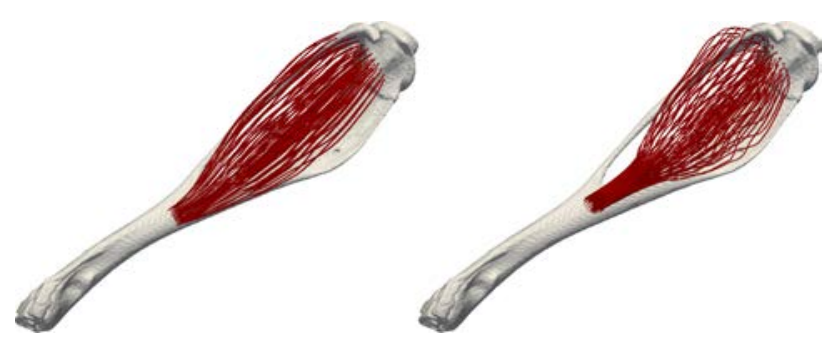

Figura 3. Simulación de una contracción con el modelo computacional. Izquierda músculo relajado, derecha músculo contraido.

\section{Conclusiones}

Es posible el desarrollo de un modelo computacional que reproduzca el comportamiento muscular en situaciones de fatiga, haciéndolo más preciso gracias a la inclusión de una variable biológica como es el remanente de glucógeno en el músculo.

\section{Referencias}

1. Calvo, B.; Ramírez, A.; Alonso, A.; Grasa, J.; Soteras, F.; Osta, R. \& Muñoz, M. J.: Passive nonlinear elastic behaviour of skeletal muscle: experimental results and model formulation.. In: J Biomech 43 (2010), Nr. 2, S. 318--325

2. Grasa, J.; Ramírez, A.; Osta, R.; Muñoz, M. J.; Soteras, F. \& Calvo, B.: A 3D active-passive numerical skeletal muscle model incorporating initial tissue strains. Validation with experimental results on rat tibialis anterior muscle.. In: Biomech Model Mechanobiol 10 (2011), Nr. 5, S. 779-787

3. Carroll, N. V.; Longley, R. W. \& Roe, J. H.: The determination of glycogen in liver and muscle by use of anthrone reagent. In: J Biol Chem 220 (1956), Nr. 2, S. 583-593 